\title{
Surgical treatment for midportion Achilles tendinopathy: a systematic review
}

\author{
T. P. A. Baltes ${ }^{1}$ R. Zwiers ${ }^{1}$ J. I. Wiegerinck ${ }^{1}$ C. N. van Dijk ${ }^{1}$
}

Received: 24 September 2015 / Accepted: 16 February 2016 / Published online: 12 March 2016

(C) The Author(s) 2016. This article is published with open access at Springerlink.com

\begin{abstract}
Purpose The aim of this study was to systematically evaluate the available literature on surgical treatment for midportion Achilles tendinopathy and to provide an overview of the different surgical techniques.

Methods A systematic review of the literature available in MEDLINE, EMBASE and the Cochrane database of controlled trials was performed. The primary outcome measure in terms of patient satisfaction and the secondary outcome measures that consisted of complication rate, pain score, functional outcome score and success rate were evaluated. The Downs \& Black checklist and the Coleman methodology scale were used to assess the methodological quality of included articles.

Results Of 1090 reviewed articles, 23 met the inclusion criteria. The included studies reported on the results of 1285 procedures in 1177 patients. The surgical techniques were divided into five categories. Eleven studies evaluated open surgical debridement, seven studies described minimally invasive procedures, three studies evaluated endoscopic procedures, one study evaluated open gastrocnemius lengthening, and one study reported on open autologous tendon transfer. Results regarding patient satisfaction $(69-100 \%)$ and complication rate $(0-85.7 \%)$ varied widely.

Conclusions This study demonstrates the large variation in surgical techniques available for treatment of midportion Achilles tendinopathy. None of the included studies
\end{abstract}

T. P. A. Baltes

t.p.baltes@amc.uva.nl

1 Department of Orthopaedic Surgery, Academical Medical Center, University of Amsterdam, P.O. Box 22660, 1100 DD Amsterdam, The Netherlands compared surgical intervention with nonsurgical or placebo intervention. Minimally invasive and endoscopic procedures yield lower complication rates with similar patient satisfaction in comparison with open procedures. Minimally invasive and endoscopic procedures might therefore prove to be the future of surgical treatment of Achilles midportion tendinopathy.

Level of evidence IV.

Keywords Midportion Achilles tendinopathy ·

Endoscopic surgery $\cdot$ Minimally invasive surgery $\cdot$ Open surgery $\cdot$ Tenotomies

\section{Introduction}

Midportion Achilles tendinopathy is a painful condition of the Achilles tendon located 2-7 cm proximal to the insertion on the calcaneus. Symptoms include pain, swelling and impaired performance. It is an over-use injury, often seen in athletes. The incidence varies from $0.2 \%$ in the general population up to $9 \%$ in recreational runners $[12,17]$.

Initially, treatment of midportion tendinopathy is nonsurgical. Various noninvasive treatment options have been described, including eccentric exercise, the use of orthoses and rest. Additionally, invasive nonsurgical techniques like extracorporeal shockwave therapy and platelet-rich plasma (PRP) injection are commonly used [39]. In approximately $25 \%$ of the patients nonsurgical treatment fails to alleviate symptoms and surgical treatment is indicated [14].

Historically, surgical treatment was performed using an open procedure $[13,26,32]$. With new insights into the aetiology of tendinopathy, new surgical procedures were developed, resulting in a large variety of surgical techniques $[19,34]$. Because of the high complication rates in 

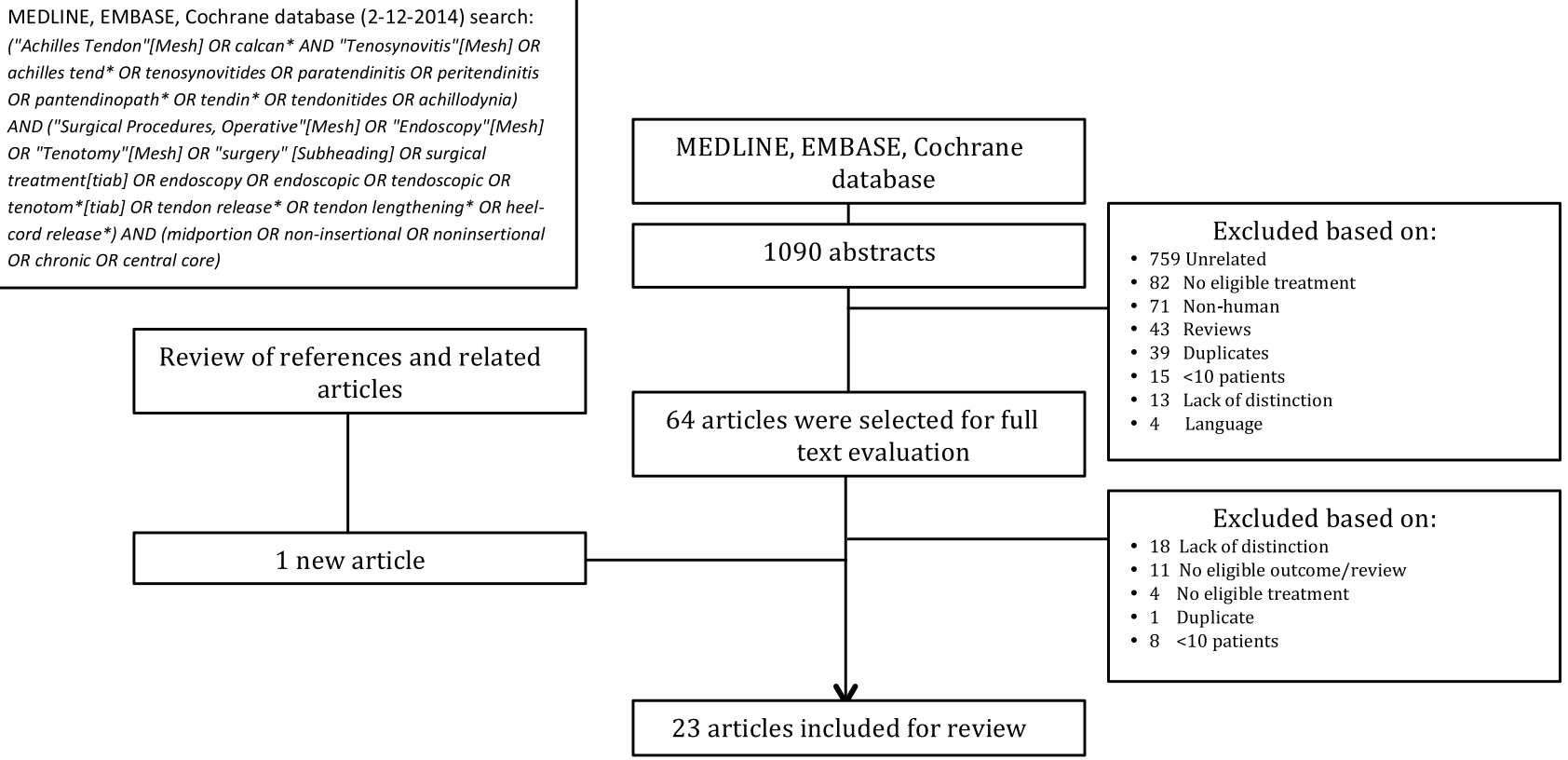

Fig. 1 Search strategy

open procedures, less invasive techniques gained popularity [16, 24, 29, 37].

Due to the variety of surgical techniques and the confusing terminology used to describe pathologies of the Achilles tendon, no study to date has provided a clear overview of the literature regarding the best surgical treatment for midportion Achilles tendinopathy. The aim of this study is to systematically evaluate the available literature on surgical treatment for midportion Achilles tendinopathy and to provide an overview of the different surgical techniques in terms of patient satisfaction and complication rate.

\section{Materials and methods}

\section{Search strategy}

A systematic review of the literature was performed. In collaboration with a clinical librarian, the databases of MEDLINE, EMBASE and the Cochrane database for controlled trials were searched (Fig. 1).

\section{Inclusion criteria}

Studies reporting on the results of surgical treatment for midportion Achilles tendinopathy in humans were included. In this study, the definition of midportion Achilles tendinopathy as described by van Dijk et al. [8] is used. Midportion Achilles tendinopathy is defined as symptoms of pain, swelling and impaired performance in combination with a histopathological diagnosis that includes, but is not limited to, the diagnosis of tendinosis $2-7 \mathrm{~cm}$ from the calcaneal insertion. Studies were eligible if they assessed the outcome measures of patient satisfaction or complication rate. Reviews and studies reporting on less than ten patients were excluded. Only studies written in English, French or German were considered eligible. Studies lacking clear distinction between midportion and insertional Achilles tendinopathy were excluded. Two authors (TB \& RZ) performed title and abstract screening independently. Subsequently, these two authors individually performed full text selection. Disagreement during study selection was settled by discussion.

\section{Data extraction}

Data on patient characteristics, surgical technique and outcome were extracted. Patient satisfaction was the primary outcome measure. Secondary outcome measures consisted of complication rate, functional outcome scores, pain scores and success rate. Complications were divided in minor and major (Table 1). Successful treatment was defined as an excellent or good outcome, or when patients were satisfied with the result.

\section{Methodological quality}

Methodological quality of included studies was assessed using the Downs \& Black checklist and the Coleman methodology scale [7, 9]. The Downs \& Black checklist 
Table 1 Classification of complications

\begin{tabular}{ll}
\hline Complications & \\
\hline Major & Minor \\
\hline AT rupture & Discomfort \\
Any reoperation & Superficial infections \\
Deep venous thrombosis & Minor wound problems \\
Reflex dystrophy & Scar tenderness/hypertrophy \\
Persisting neuralgia & Mild form of paraesthesia \\
Deep infections/major wound problems & Prolonged hospitalisation \\
\hline
\end{tabular}

was designed to evaluate the methodological quality of randomised and nonrandomised studies. It consists of a 27-item checklist with a highest possible score of 33 points. The Coleman methodology scale was designed to evaluate the methodological quality of studies on Achilles tendinopathies. The checklist consists of two parts and has a maximum possible score of 100 points. Two authors (TB \& JW) assessed the included studies independently on methodological quality. Correlations between success rate and both the Coleman scale and Downs \& Black checklist were calculated.

\section{Data presentation and statistical analysis}

Due to the heterogeneity of the data, results were not pooled. Outcome data were presented per study. Ranges of outcome were reported per type of surgical procedure. To calculate the correlations of nonparametric data, the Spearman's rho correlation coefficient was used. Correlation with a $p$ value $<0.05$ was considered significant.

\section{Results}

After removal of duplicates, the search yielded 1090 articles. Based on title and abstract screening, 1026 articles were excluded (Fig. 1). The remaining 64 articles were eligible for full text evaluation. Forty-two articles were excluded after full text selection. Finally, after screening references of included articles and the related literature, one article was added [6]. A total of 23 studies were included in this study (Table 2; Appendix 1 in Table 5) [1-4, 6, 10, 11, $13,15,18,20-24,26-31,33,36]$.

\section{Population characteristics}

The studies reported on a total of 1177 patients with 1285 affected tendons. $62.7 \%$ of the patients was male. Seven studies did not report on gender distribution $[11,13,26,29$, $30,33,36]$. The weighted mean age was 40.2 years. The remaining seven studies did not adequately report on age $[1,10,21,26,29,33,36]$.

\section{Surgical techniques}

In this review, the techniques were roughly grouped into five types of procedures. Eleven studies reported open techniques as treatment of midportion Achilles tendinopathy $[4,11,13,15,18,21,26-29,31]$. Seven studies evaluated minimally invasive procedures $[1-3,6,20,24,36]$. Three studies reported on endoscopic techniques [22, 30, 33], one study evaluated gastrocnemius lengthening by an open procedure [10], and one reported on a technique for open resection of the distal Achilles tendon, followed by interposition of FHL graft [23]. Techniques were classified as minimally invasive based on descriptions in the studies. In six of the included studies reporting minimally invasive techniques, incisions were smaller than $2 \mathrm{~cm}$ (Appendix 2 in Table 6).

\section{Open surgery}

Eleven studies described the outcome of an open surgical approach $[4,11,13,15,18,21,26-29,31]$. There is a large variation in techniques; however, each technique consisted of the release of the tendon (adhesiolysis, release or excision of the paratenon), debridement of degenerative tissue, longitudinal tenotomies or a combination of these (Table 2; Appendix 2 in Table 6). Four studies compared the results of release of the tendon with or without tenotomies, with a group of patients that additionally underwent debridement of degenerative tissue $[11,15,28,29]$. One compared the results between a group of patients that underwent debridement without suturing or augmentation with a group in which the tendon was augmented using fibres of the soleus muscle [4]. In another study, three groups were distinguished: no debridement of the tendon was performed in group A. Group B and C consisted of patients with tendinosis and extensive tendinosis. Both groups were treated by excision of degenerations, followed by side-to-side suture for patients in group B or reconstruction with a turndown flap in group C [26].

None of the studies reported on patient satisfaction (Table 3). Complication rates were adequately reported in eight studies and ranged from 0 up to $85.7 \%$ (Table 3) [4, $11,13,18,21,27,29,31]$. Success rates varied from 73.1 up to $100 \%$ (Table 4) [13, 15, 26-28, 31].

\section{Minimally invasive tendon stripping/tenotomies}

Minimally invasive procedures were described in seven included studies [1-3, 6, 20, 24, 36]. Five articles described a technique to perform a release of the Achilles tendon 
Table 2 Overview of included studies

\begin{tabular}{|c|c|c|c|c|}
\hline Study & $N$ patients ( $N$ tendons) & Surgical technique & Coleman & $D \& B$ \\
\hline \multicolumn{5}{|l|}{ Open debridement } \\
\hline \multirow[t]{2}{*}{ Benazzo et al. [4] } & A. $20(20)$ & $\begin{array}{l}\text { A. Open surgery: multiple longitudinal tenotomies and excision } \\
\text { degenerations }\end{array}$ & 54 & 22 \\
\hline & B. $32(32)$ & B. Open surgery: excision degeneration + soleus fibres transfer & & \\
\hline \multirow[t]{2}{*}{ Johnston et al. [11] } & A. $10(10)$ & A. Open surgery: excision inflamed paratenon and decompression AT & 29 & 7 \\
\hline & B. $7(7)$ & $\begin{array}{l}\text { B. Open surgery: excision inflamed paratenon, decompression AT }+ \text { debride- } \\
\text { ment degenerations }\end{array}$ & & \\
\hline Kvist and Kvist [13] & $182(201)$ & $\begin{array}{l}\text { Open surgery: removal adhesions between paratenon, crural fascia and } \\
\text { skin }+ \text { excision thickened paratenon }\end{array}$ & 27 & 14 \\
\hline \multirow[t]{2}{*}{ Lohrer and Nauck [15] } & A. $11(15)$ & A. Open surgery: release AT + transachillear scarification & 60 & 23 \\
\hline & B. $23(24)$ & $\begin{array}{l}\text { B. Open surgery: release AT + excision intratendinous lesions }+ \text { transachil- } \\
\text { lear scarification }\end{array}$ & & \\
\hline Maffulli et al. [18] & $10(10)$ & $\begin{array}{l}\text { Open surgery: excision paratenon, multiple longitudinal tenotomies and exci- } \\
\text { sion of degenerations }\end{array}$ & 39 & 10 \\
\hline Maffulli et al. [21] & $86(86)$ & $\begin{array}{l}\text { Open surgery: excision paratenon, multiple longitudinal tenotomies + exci- } \\
\text { sion degenerations }\end{array}$ & 69 & 14 \\
\hline \multirow[t]{3}{*}{ Nelen et al. [26] } & A. (93) & A. Open surgery: release AT (not ventrally) + excision inflamed paratenon & 42 & 16 \\
\hline & B. (26) & B. Open surgery: debridement tendinosis & & \\
\hline & C. $(24)$ & $\begin{array}{l}\text { C. Open surgery: debridement tendinosis (reinforcement with turned-down } \\
\text { tendon flap) }\end{array}$ & & \\
\hline Ohberg et al. [27] & $24(24)$ & $\begin{array}{l}\text { Open surgery: excision hypertrophic paratenon and debridement of } \\
\text { degenerations through a longitudinal incision }\end{array}$ & 52 & 15 \\
\hline \multirow[t]{2}{*}{ Paavola et al. [29] } & A. $171(171)$ & A. Open surgery: excision adhesions between crural fascia and paratenon & 24 & 9 \\
\hline & B. $50(50)$ & B. Open surgery: debridement intratendinous lesions & & \\
\hline \multirow[t]{2}{*}{ Paavola et al. [28] } & A. $16(16)$ & A. Open surgery: excision adhesions between crural fascia and paratenon & 56 & 14 \\
\hline & B. $26(26)$ & $\begin{array}{l}\text { B. Open surgery: excision adhesions between crural fascia and para- } \\
\text { tenon }+ \text { debridement intratendinous lesions }\end{array}$ & & \\
\hline Sarimo and Orava [31] & $24(24)$ & Open surgery: fascial adhesiolysis and radiofrequency microtenotomy & 36 & 20 \\
\hline \multicolumn{5}{|c|}{ Minimally invasive tendon stripping/tenotomies } \\
\hline Alfredson et al. [2] & $10(10)$ & Minimally invasive: US-CD-guided release ventral AT & 48 & 17 \\
\hline \multirow[t]{2}{*}{ Alfredson $[1]^{\mathrm{a}}$} & A. $15(18)$ & A. Minimally invasive: US-CD-guided release ventral AT & 41 & 17 \\
\hline & B. $16(19)$ & B. Minimally invasive: US-CD-guided release ventral AT by use of a needle & & \\
\hline Alfredson $[1]^{\mathrm{a}}$ & $72(88)$ & Minimally invasive: US-CD-guided release ventral AT & 30 & 14 \\
\hline Alfredson et al. [3] & $13(13)$ & Minimally invasive: US-CD-guided release ventral AT & 46 & 17 \\
\hline Calder et al. [6] & $32(34)$ & Minimally invasive: Release AT and excision plantaris tendon & 59 & 21 \\
\hline Maffulli et al. [20] & $39(39)$ & Minimally invasive: multiple percutaneous longitudinal tenotomies & 59 & 20 \\
\hline Naidu et al. [24] & $26(29)$ & $\begin{array}{l}\text { Minimally invasive: circumferential AT release with a tracheal hook }+ \text { peri- } \\
\text { tendinous infusion of corticosteroids }\end{array}$ & 40 & 17 \\
\hline Testa et al. [36] & $63(63)$ & $\begin{array}{l}\text { Minimally invasive: multiple US-guided percutaneous longitudinal } \\
\text { tenotomies }\end{array}$ & 65 & 20 \\
\hline \multicolumn{5}{|l|}{ Endoscopic procedures } \\
\hline Maquirriain [22] & $24(27)$ & Endoscopic: debridement paratenon + two longitudinal tenotomies & 52 & 13 \\
\hline Pearce et al. [30] & $11(11)$ & Endoscopic: debridement paratenon + release of plantaris tendon & 60 & 13 \\
\hline $\begin{array}{l}\text { Steenstra and van Dijk } \\
\text { [33] }\end{array}$ & $16(16)$ & Endoscopic: debridement paratenon + release of plantaris tendon & 26 & 11 \\
\hline \multicolumn{5}{|c|}{ Open surgery: gastrocnemius lengthening } \\
\hline Duthon et al. [10] & $13(15)$ & Open surgery: gastrocnemius lengthening & 65 & 15 \\
\hline \multicolumn{5}{|c|}{ Open surgery: autologous tendon transfer } \\
\hline Martin et al. [23] & $44(44)$ & Open surgery: excision AT + FHL transfer & 54 & 21 \\
\hline
\end{tabular}

Outlined are the number of included patients; reported surgical technique; and methodological quality

$A T$ Achilles tendon, $U S$ ultrasound, $C D$ colour doppler

a Same study comparing release of ventral AT with knife versus needle 


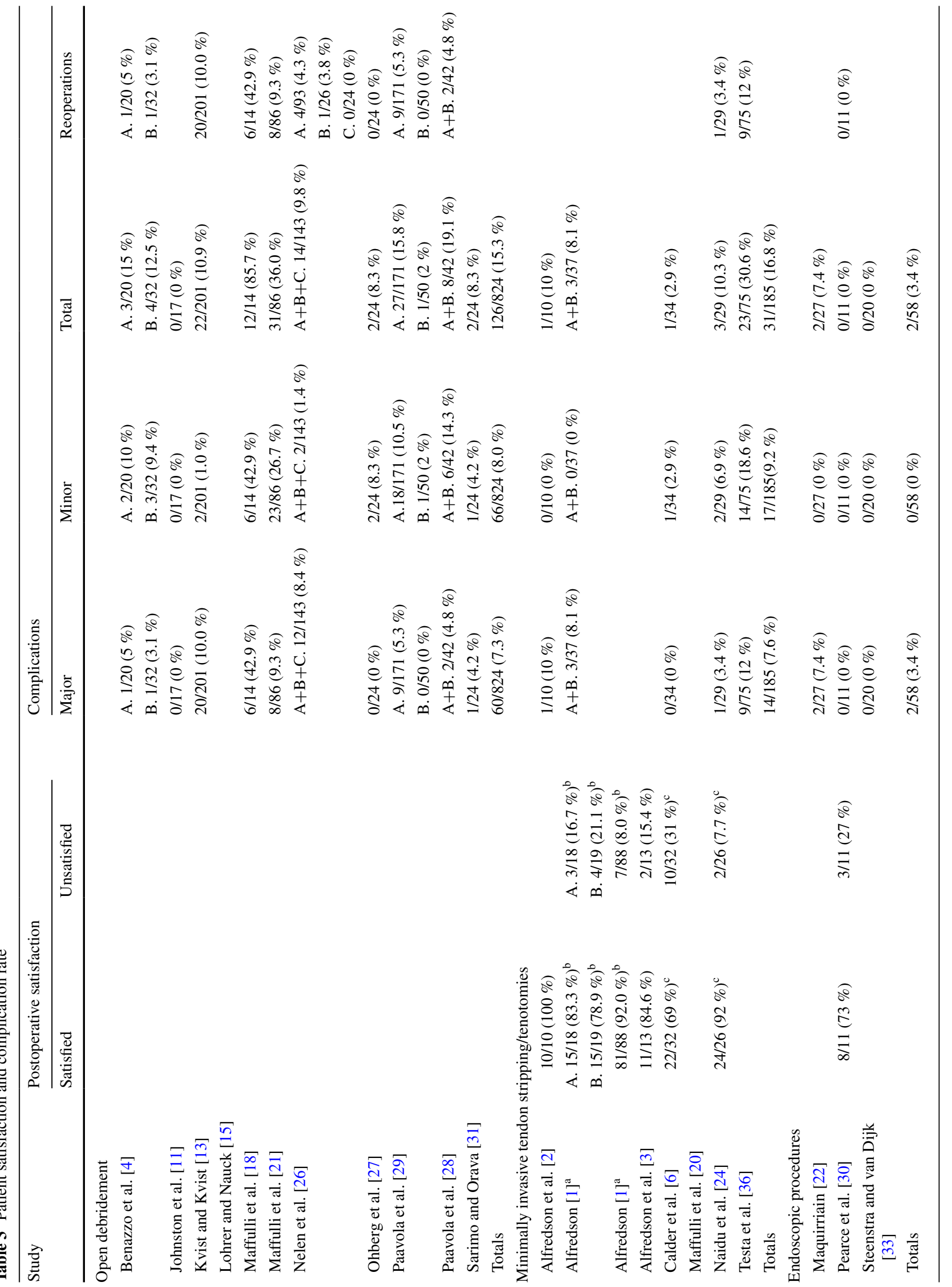


Patient satisfaction was reported in five studies and ranged from 69 up to $100 \%$ (Table 3). [1-3, 6, 24]. Complications rates were adequately reported in four studies, ranging from 2.9 up to $30.6 \%$ (Table 3 ) $[2,6,24,36]$. Success rates varied from 69 up to $100 \%$ (Table 4) $[1-3,6,20$, $24,36]$.

\section{Endoscopic procedures}

Three studies reported on the outcome of endoscopic procedures $[22,30,33]$. In all procedures, debridement of the paratenon was performed, with additional release of the plantaris tendon in two studies [30,33] and additional longitudinal tenotomies in one study [22] (Table 2, Appendix 2 in Table 6).

Only one study reported on patient satisfaction; in this study $73 \%$ of patients was satisfied (Table 3) [30]. Complications rates varied from 0 to $7.4 \%$ (Table 3) [22, 30, 33]. Success rates varied from 73 up to $100 \%$ (Table 4) [22, 30].

\section{Open surgery: gastrocnemius lengthening}

One study evaluated gastrocnemius lengthening through an open procedure (Table 2, Appendix 2 in Table 6) [10]. Using this technique, a satisfaction rate of $92.3 \%$ was achieved in combination with $0 \%$ complications (Table 3 ). A success rate of $92.3 \%$ was achieved (Table 4).

\section{Open surgery: autologous tendon transfer}

One study reported on autologous tendon transfer [23]. The technique consisted of resection of the distal Achilles tendon, followed by interposition of the flexor hallucis longus (FHL) tendon (Table 2, Appendix 2 in Table 6).

The study reported that patient satisfaction was achieved in $86 \%$ of the patients (Table 3). Complications occurred in $11.4 \%$ of the patients (Table 3). A success rate of $86 \%$ was achieved (Table 4).

\section{Methodological quality}

The assessment of the methodological quality using the Downs \& Black checklist and the Coleman methodological scale resulted in a median score of 12.0 (IQR 10.0-13.25) and 57.5 (IQR 40.0-64.25), respectively (Table 2).

There was no significant correlation between success rate and both Coleman score and Downs \& Black score. However, a significant positive correlation was found between year of publication and Coleman score (rho: 0.53, $p<0.01)$, and year of publication and Downs \& Black score (rho $0.66, p<0.01$ ).

\section{Discussion}

The most important finding of the present study is the large variation in surgical techniques available for the treatment of midportion Achilles tendinopathy. Additionally, it demonstrates that minimally invasive and endoscopic procedures have lower complication rates with comparable patient satisfaction in comparison with open procedures. Due to low methodological quality of included studies in combination with large heterogeneity in population, used techniques and reported outcome measures, we refrained from data pooling.

Hitherto, one review evaluating surgical treatment of Achilles tendinopathy was performed [35]. In this study from 2001 a mean success rate of $77.4 \%$ was reported [35]. Additionally, a negative correlation between success rate and methodological quality in studies on the topic of surgical treatment of tendinopathy was established [35]. In contrast to that review, we found no correlation between effectiveness and methodological quality. However, we found a positive correlation between year of publication and Coleman score, in line with a previous review on insertional tendinopathy [38]. This implicates that in current research on Achilles tendinopathy the methodological quality is improving.

Studies on open surgery reported inconsistent results regarding patient satisfaction and the complication rates varied widely. Particularly high complication rates were observed in studies evaluating the outcome of multiple tenotomies via an open procedure $[4,18,21]$.

In general, good results regarding patient satisfaction and complication rates were reported in studies on minimally invasive surgery. Most of these studies reported on minimally invasive release of the Achilles tendon or minimally invasive longitudinal tenotomies of the Achilles tendon. One study evaluated the results of excision of the plantaris tendon [6]. In this study promising results were reported. However, more studies are needed to support these findings.

Minimally invasive procedures are assumed to have lower complication rates. Most studies evaluating minimally invasive techniques reported low complication rates (Table 3). However, a particularly high complication rate was observed in the study evaluating multiple percutaneous tenotomies [36].

Excellent results regarding functional outcome and postoperative pain were reported in three small series on endoscopic surgery. There were significant differences in the evaluated endoscopic procedures. Maquirriain et al. [22] reported the results of multiple endoscopic longitudinal tenotomies where in the other studies endoscopic release of the Achilles tendon in combination with release 
of the plantaris tendon was evaluated [30, 33]. Compared to the study by Pearce et al. a higher complication rate was observed in this study.

One study evaluating the results of gastrocnemius lengthening was included in this review [10]. Although promising results are reported, the study evaluated a mere 13 patients at final follow-up. A recent study reported less promising results regarding self-reported sport function in patients treated for Achilles tendinopathy with gastrocnemius lengthening [25].

One study on FHL transfer was included [23]. Good results were reported; however, a high complication rate was observed. The included retrospective case series reported on 44 patients with a mean age of 58.2 years. However, patients affected by midportion tendinopathy tend to be younger, and a wish for return to high-level sport is often present.

The most important limitation of this review is the limited level of evidence of included articles resulting in a high risk of bias. In addition, the lack of or incomplete reportage of our primary and secondary outcome measures made for an arduous comparison. In addition, the included studies used a large variety of heterogeneous outcome measures to measure functional outcome and pain. Therefore, caution should be taken when interpreting the results presented in this review. Another limitation is the confusing terminology used to describe the various pathological conditions of the Achilles tendon [8].

Despite the low level of evidence of the included study, this systematic review is of clinical significance [5]. This study is the first systematic review to compare surgical techniques for their effectiveness on patient satisfaction and complication rate. The study provides a comprehensive overview and clearly demonstrates the variation per surgical technique in outcome of patient satisfaction and complication rates.

We strongly encourage future studies to be conducted using validated instruments to assess pain and functional outcome. As often advocated, larger populations, prospective studies and long-term follow-up studies are needed to be conclusive on the best surgical treatment option of midportion Achilles tendinopathy.
In addition, no comparative study of surgical treatment and nonsurgical treatment or placebo intervention has been conducted. Therefore, no additional benefit of surgery over nonsurgical treatment, placebo intervention or wait-and-see policy has been established. Future research should therefore strive to compare surgical treatment with nonsurgical or placebo intervention.

Furthermore, as the exact pathophysiology of midportion tendinopathy is still poorly understood, current surgical techniques address a range of hypothetical abnormalities with varying results (Appendix 1 in Table 5). Future research should aim to determine whether the extent of the pathology influences the required surgical approach.

\section{Conclusion}

The study provides a comprehensive overview of the current literature and clearly demonstrates the variation in outcome of patient satisfaction and complication rates. None of the included studies compared surgical treatment with nonsurgical treatment or placebo intervention. However, minimally invasive and endoscopic procedures result in lower complication rates compared to open surgical procedures. Minimally invasive and endoscopic procedures might therefore prove to be the future of surgical treatment of Achilles midportion tendinopathy.

\section{Compliance with ethical standards}

\section{Conflict of interest None.}

Open Access This article is distributed under the terms of the Creative Commons Attribution 4.0 International License (http://creativecommons.org/licenses/by/4.0/), which permits unrestricted use, distribution, and reproduction in any medium, provided you give appropriate credit to the original author(s) and the source, provide a link to the Creative Commons license, and indicate if changes were made.

\section{Appendix 1}

See Table 5. 


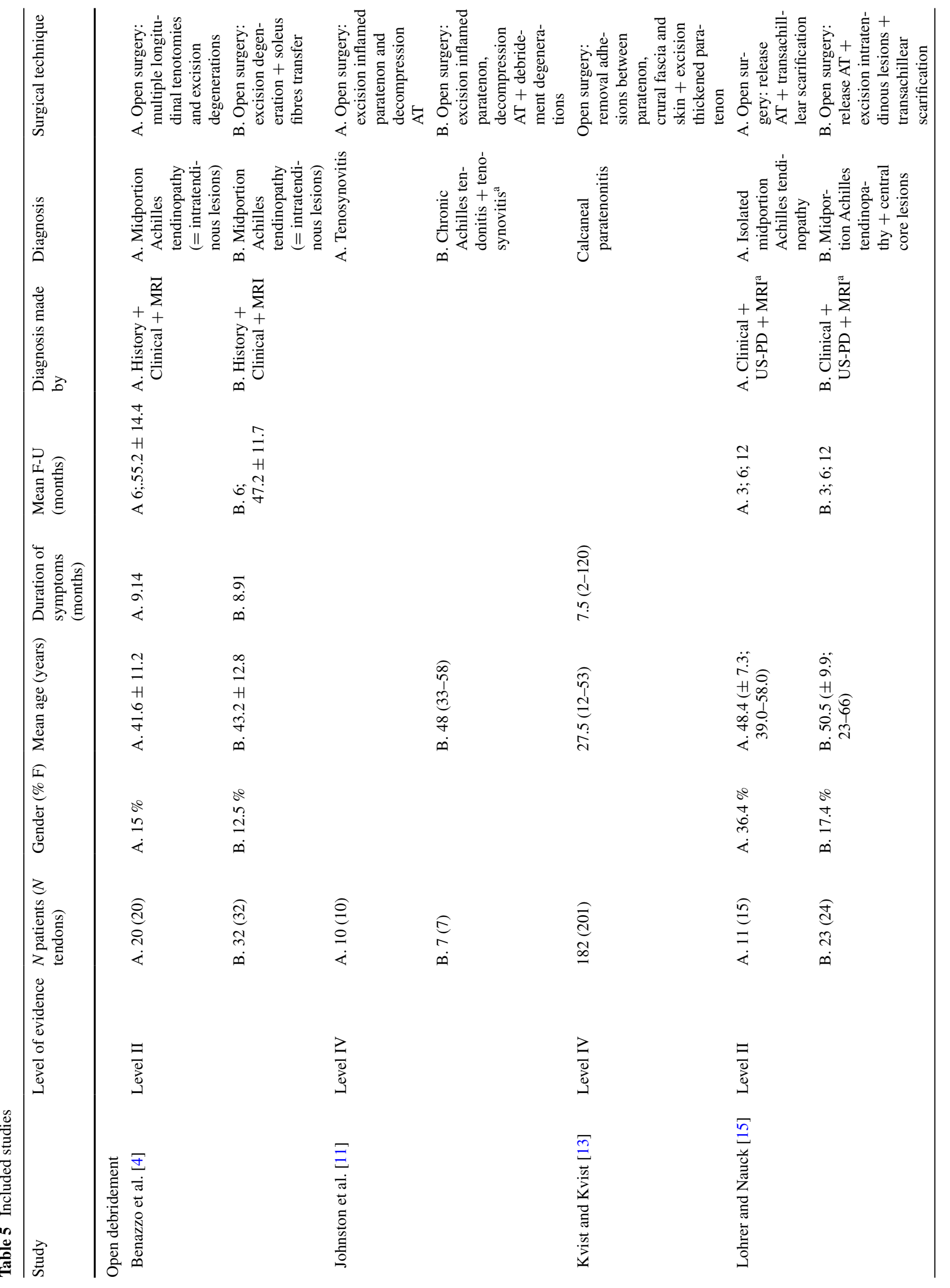




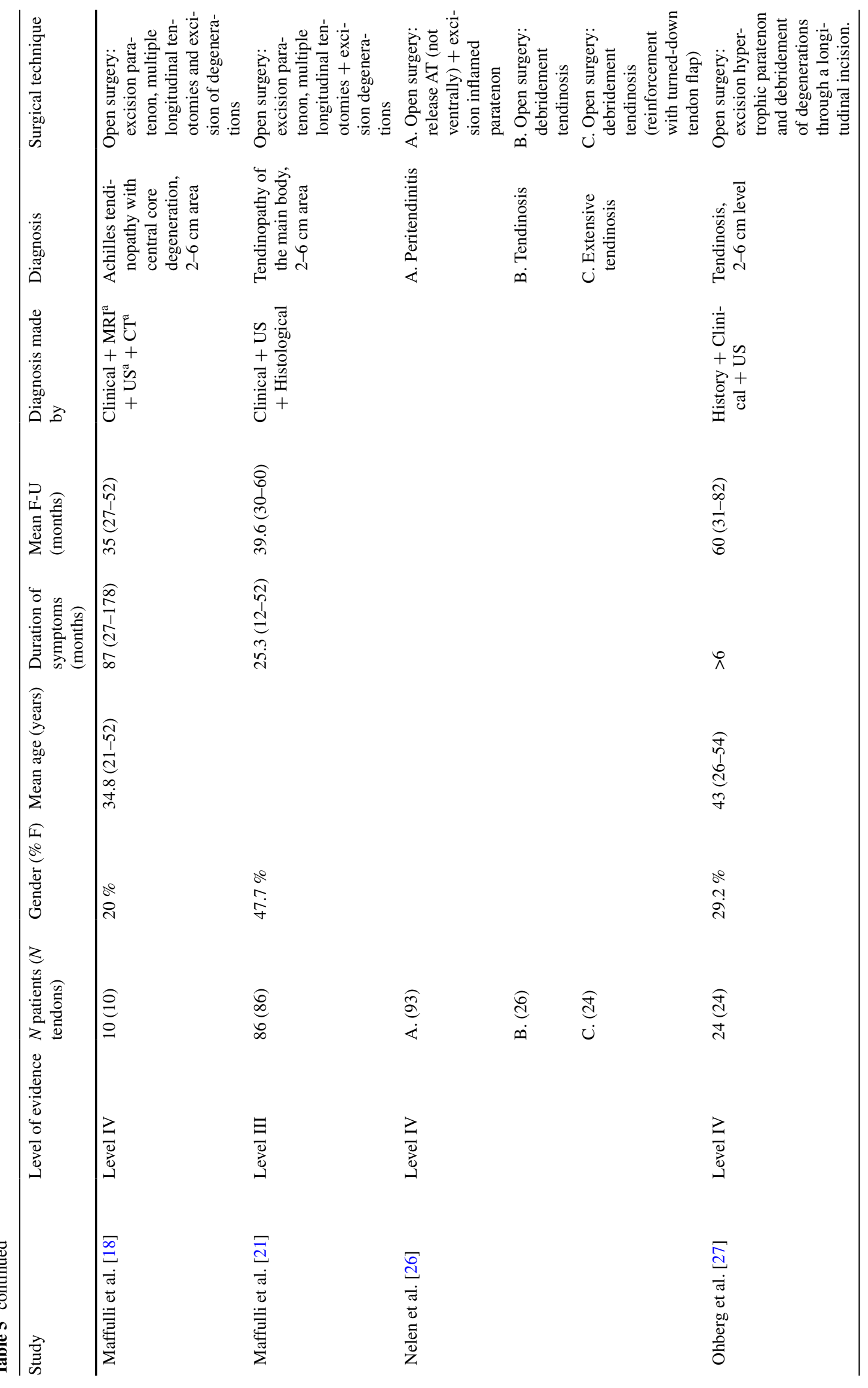




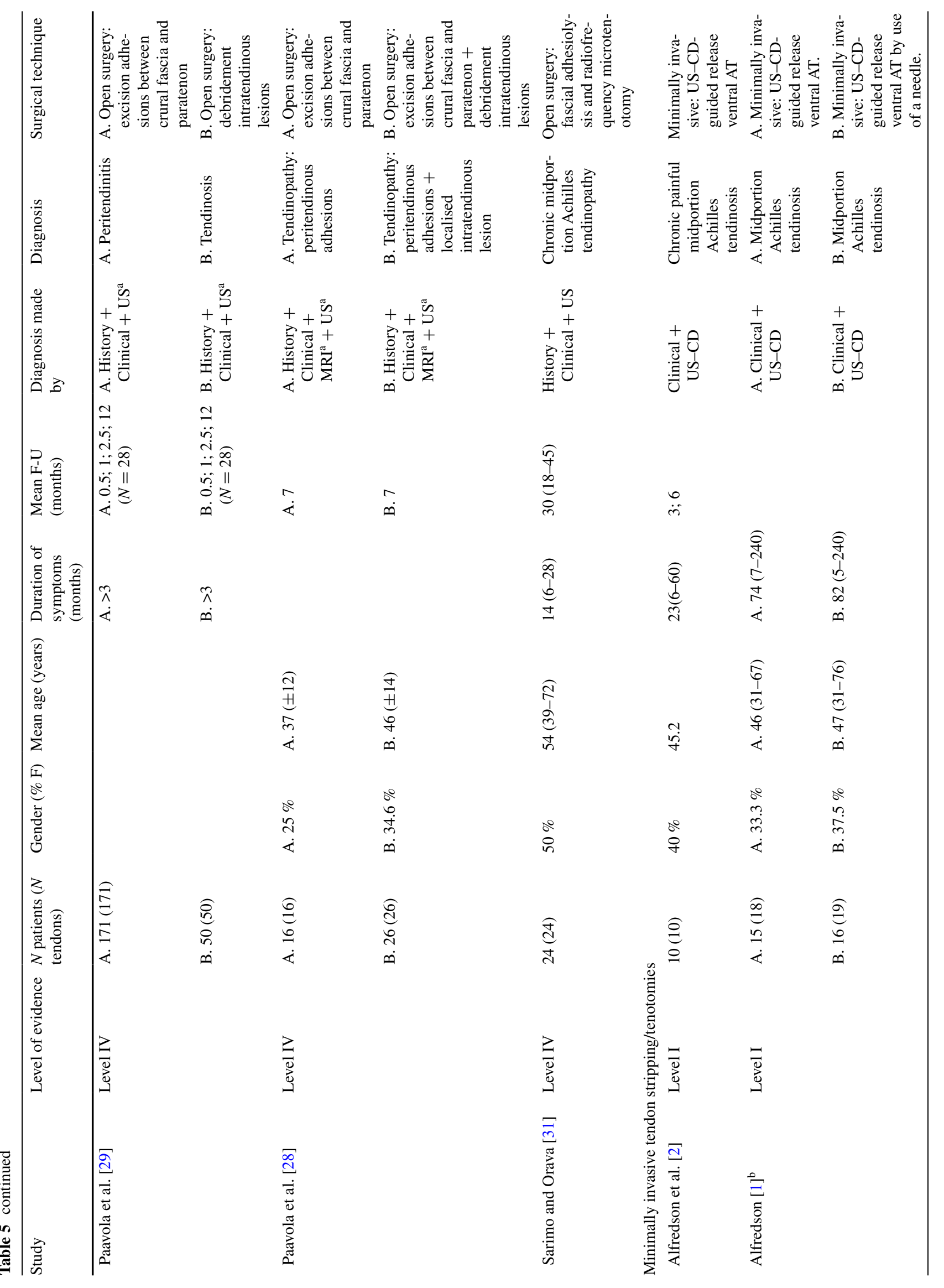




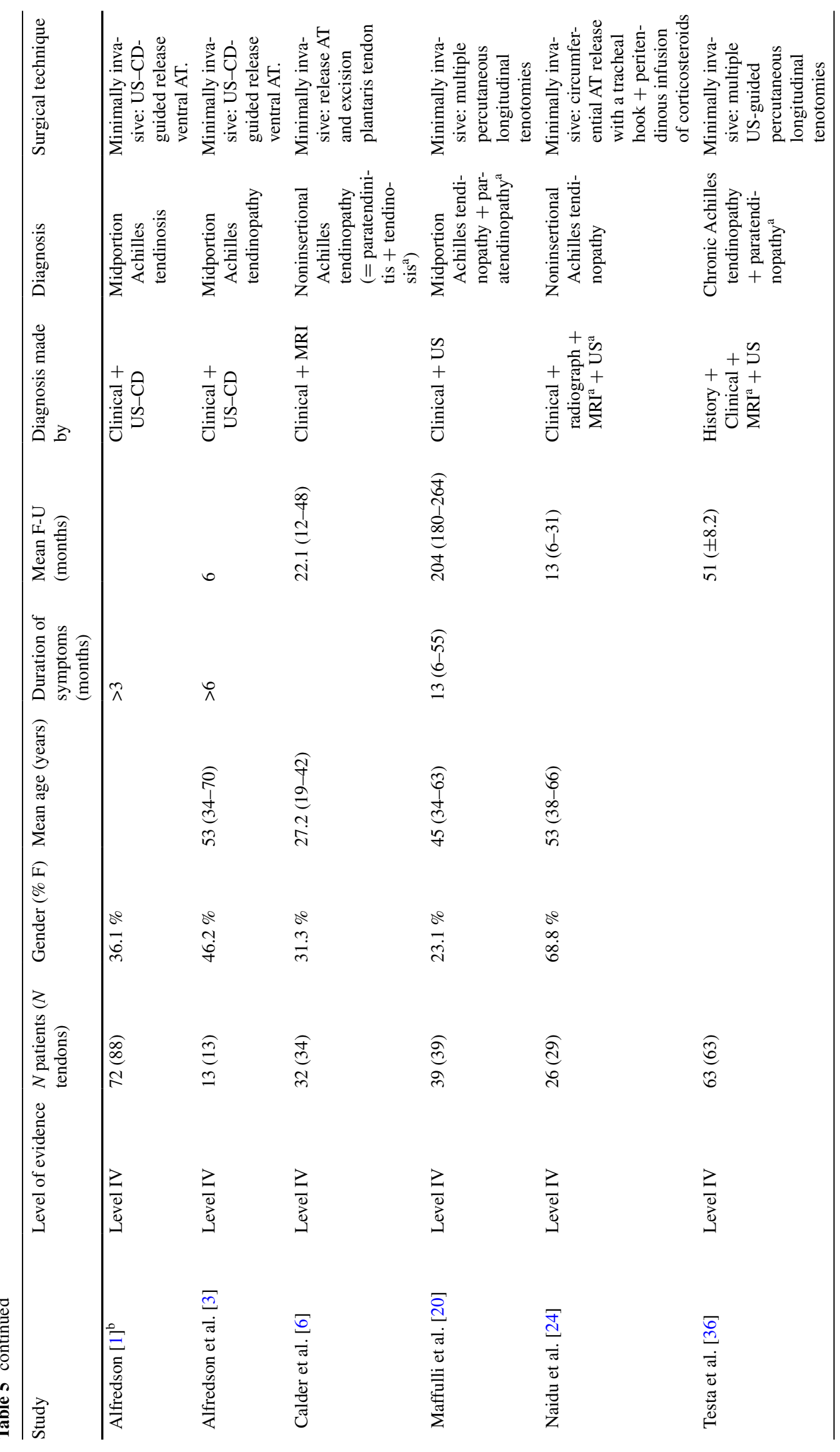




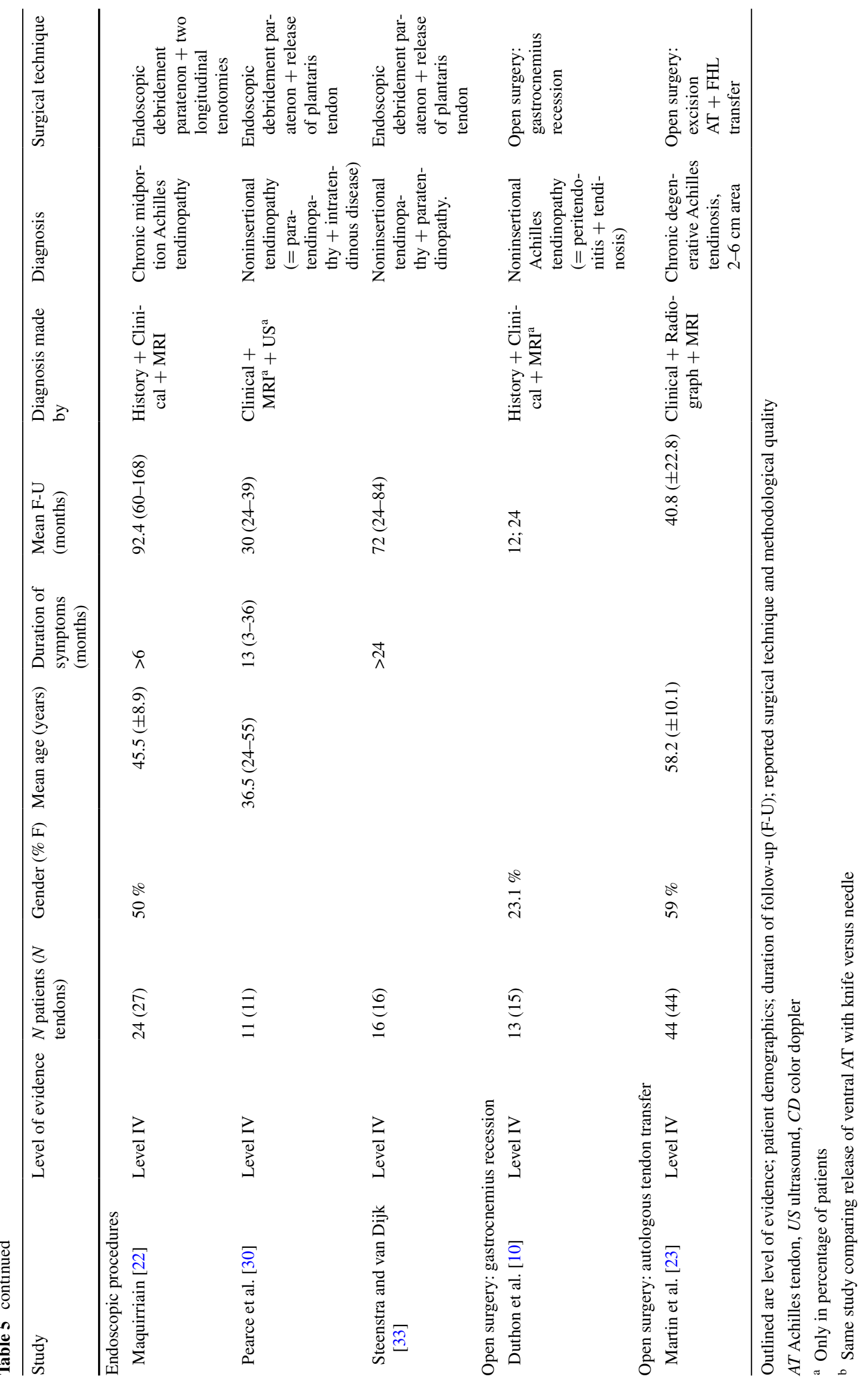




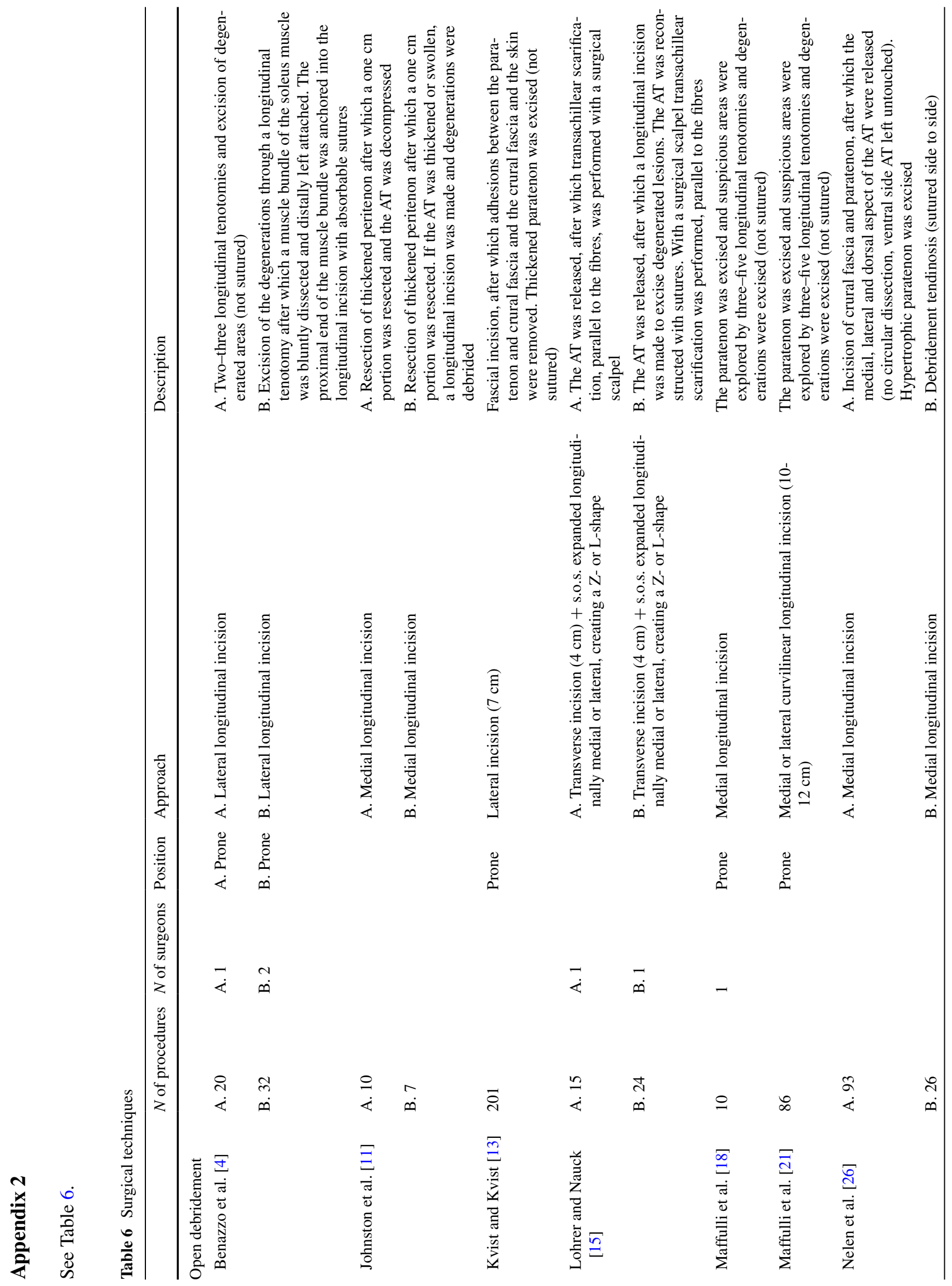




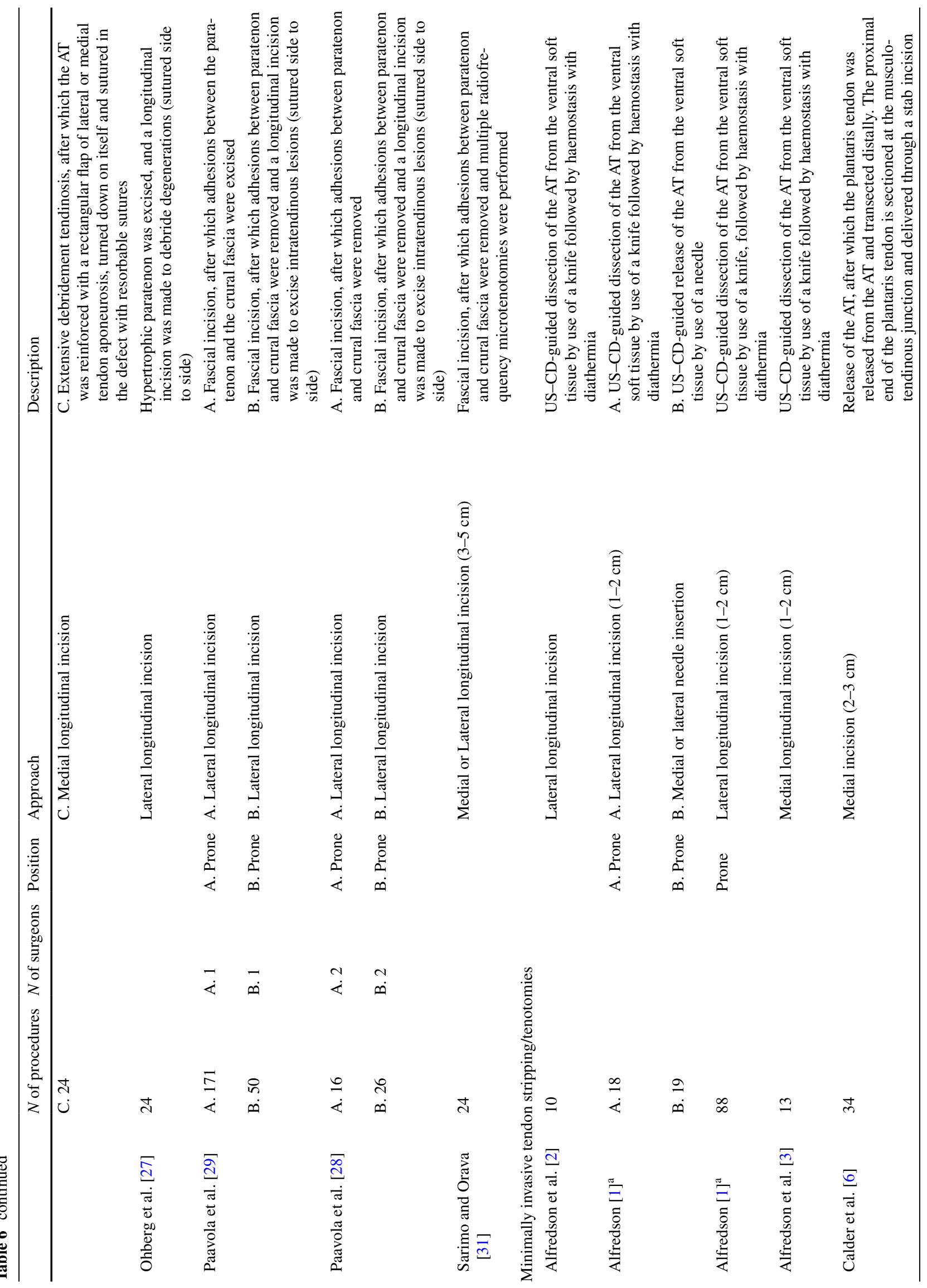




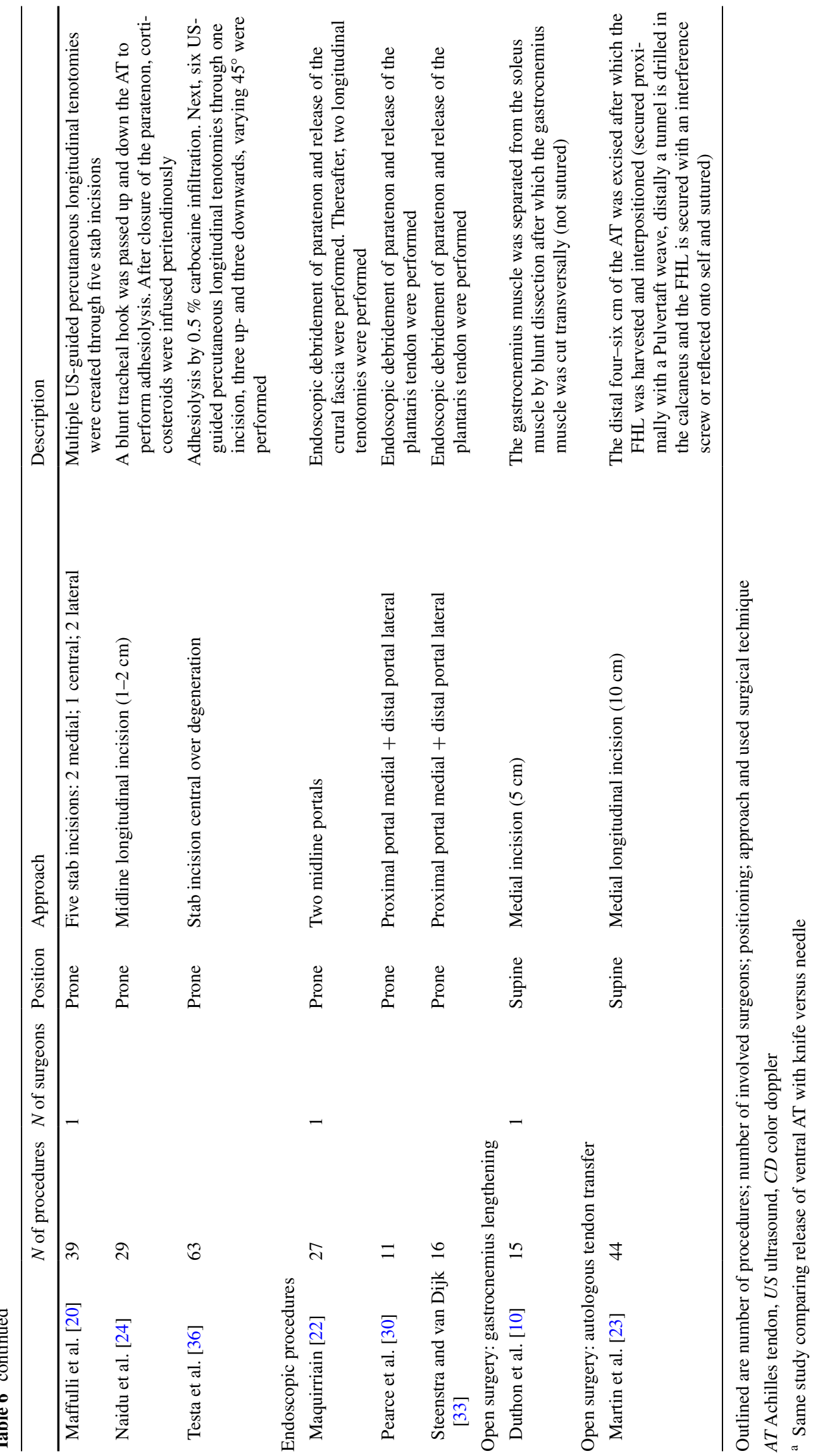




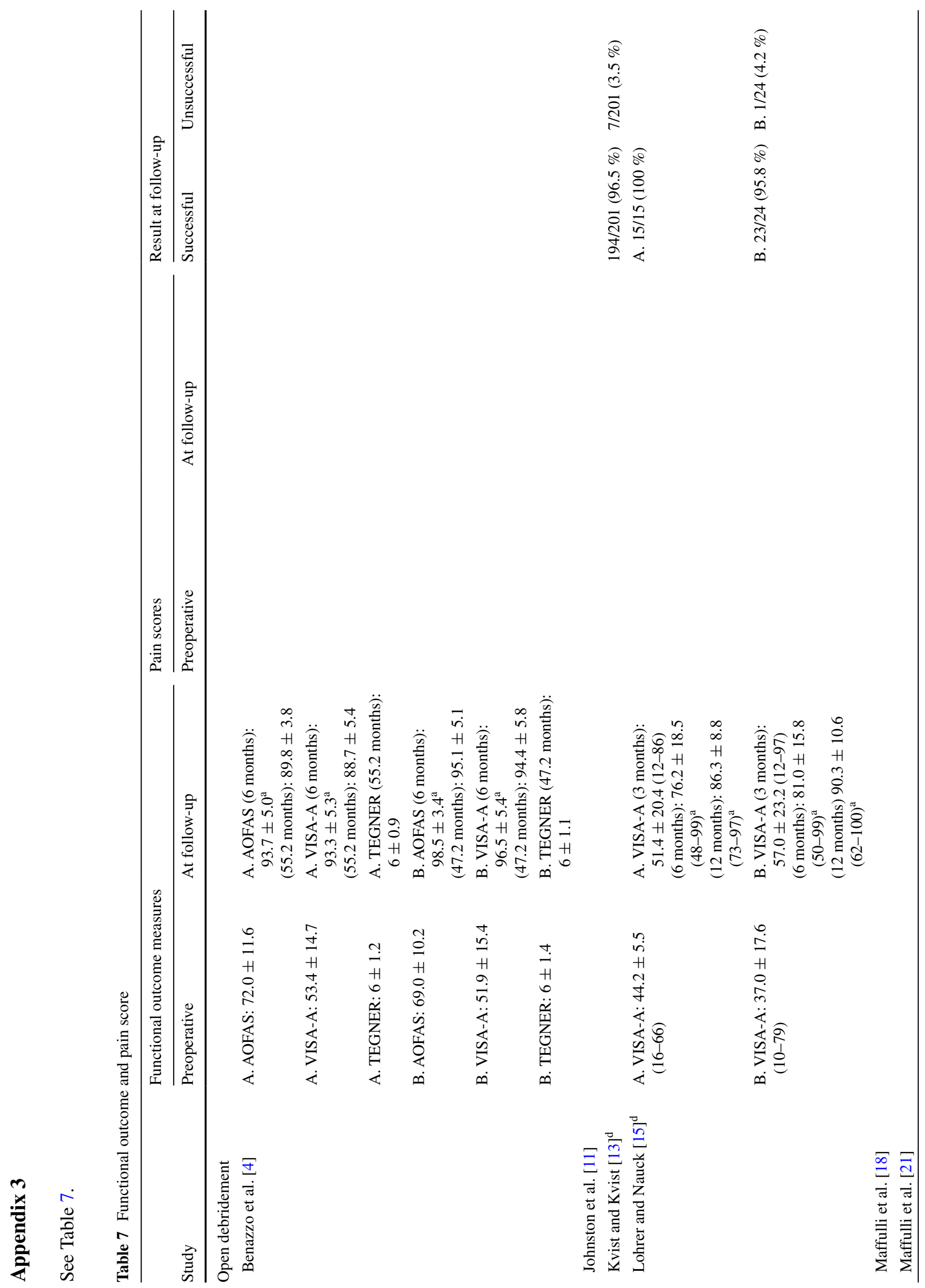




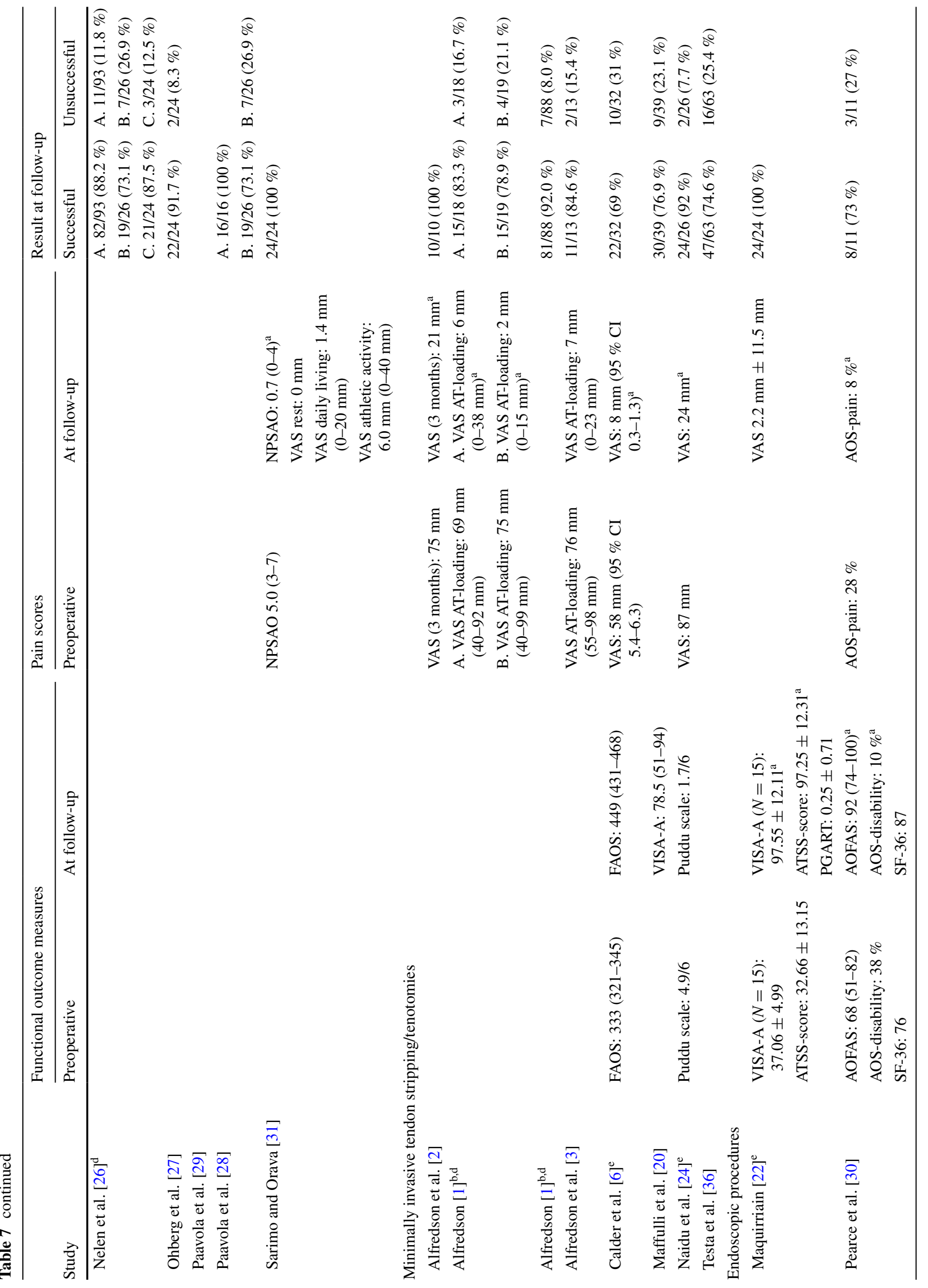




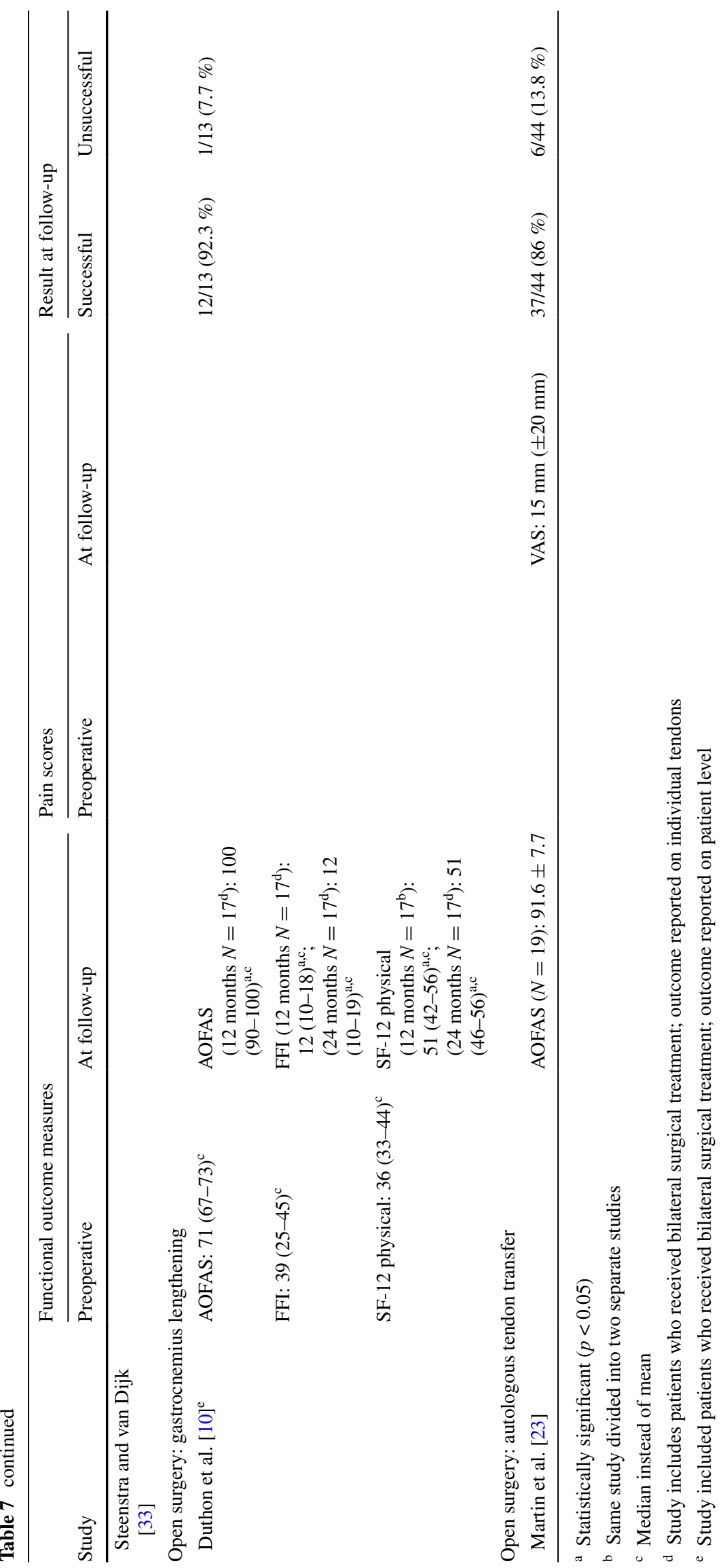




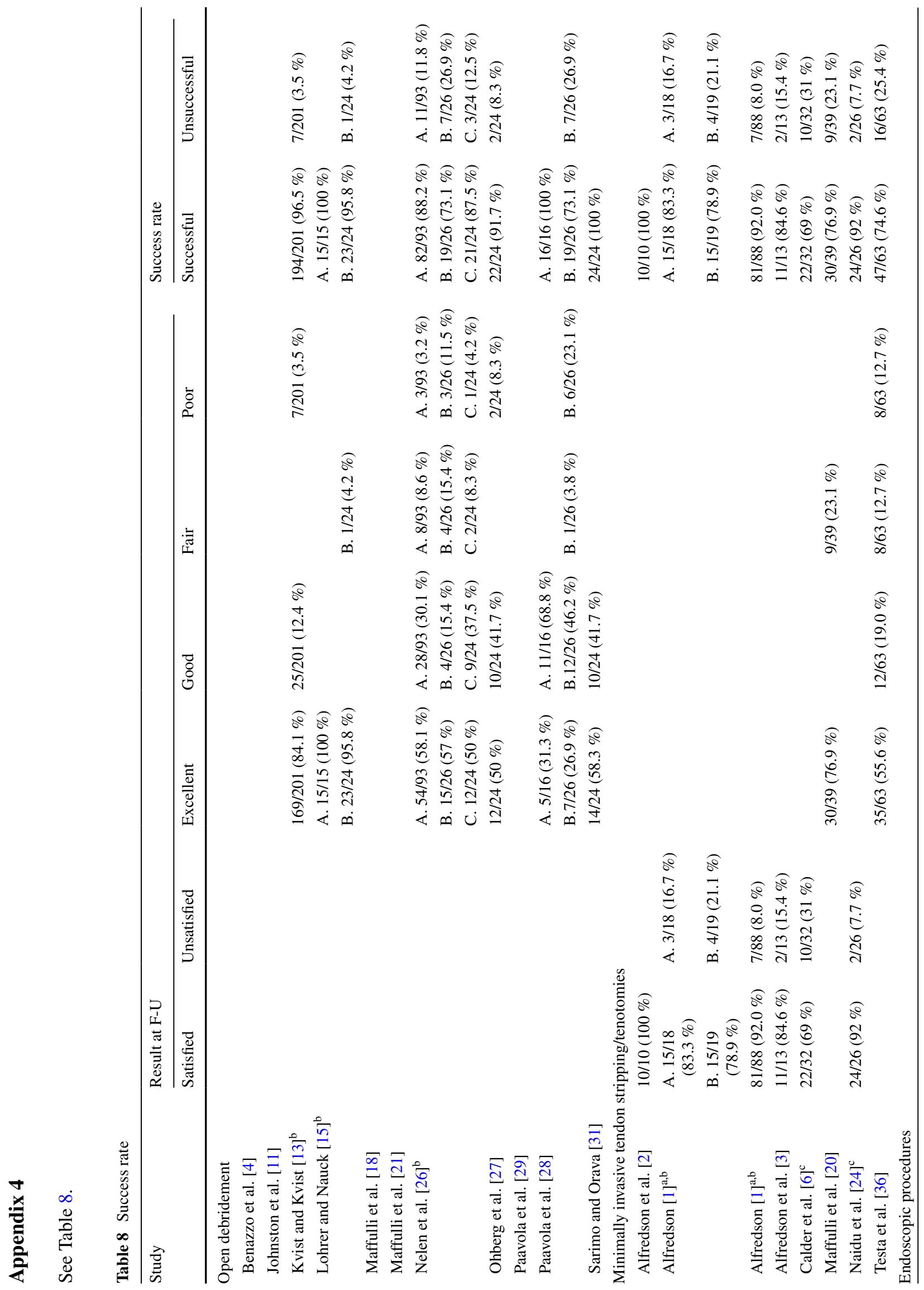




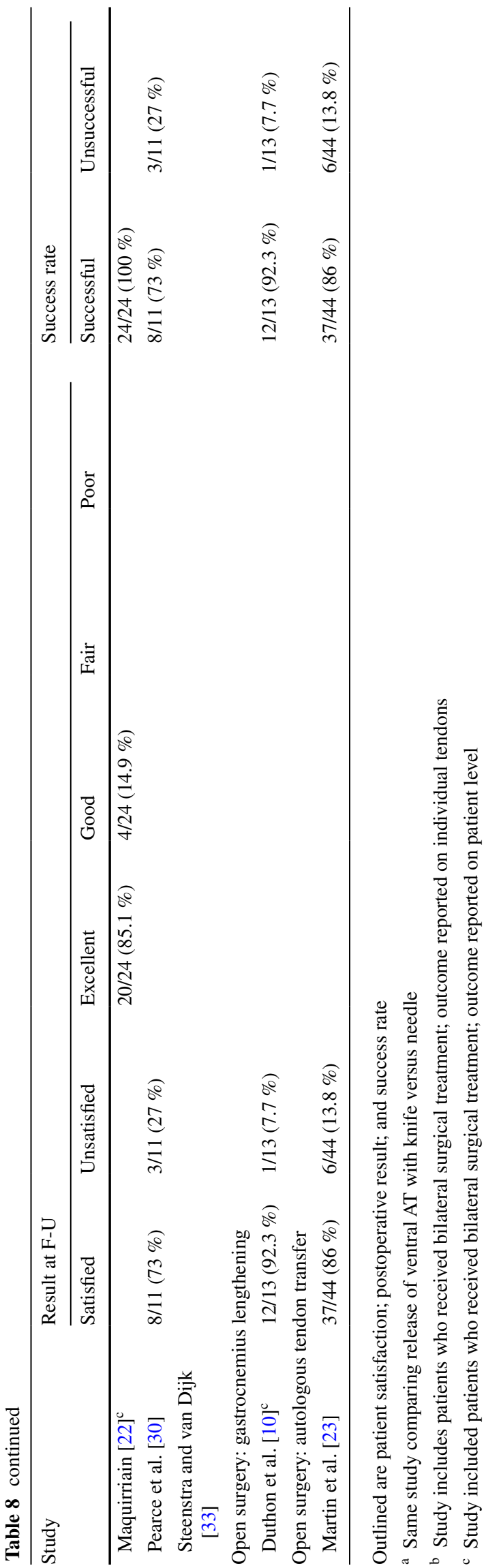

\section{References}

1. Alfredson H (2011) Ultrasound and Doppler-guided mini-surgery to treat midportion Achilles tendinosis: results of a large material and a randomised study comparing two scraping techniques. Br J Sports Med 45:407-410

2. Alfredson H, Ohberg L, Zeisig E, Lorentzon R (2007) Treatment of midportion Achilles tendinosis: similar clinical results with US and CD-guided surgery outside the tendon and sclerosing polidocanol injections. Knee Surg Sports Traumatol Arthrosc 15:1504-1509

3. Alfredson H, Spang C, Forsgren S (2012) Unilateral surgical treatment for patients with midportion Achilles tendinopathy may result in bilateral recovery. Br J Sports Med 48:1421-1424

4. Benazzo F, Zanon G, Klersy C, Marullo M (2014) Open surgical treatment for chronic midportion Achilles tendinopathy: faster recovery with the soleus fibres transfer technique. Knee Surgery Sport Traumatol Arthrosc. doi:10.1007/s00167-014-3232-x

5. Bhandari M, Montori VM, Devereaux PJ, Wilczynski NL, Morgan D, Haynes RB (2004) Doubling the impact: publication of systematic review articles in orthopaedic journals. J Bone Joint Surg Am 86-A:1012-1016

6. Calder JDF, Freeman R, Pollock N (2014) Plantaris excision in the treatment of non-insertional Achilles tendinopathy in elite athletes. Br J Sports Med 49:1532-1534

7. Coleman BD, Khan KM, Maffulli N, Cook JL, Wark JD (2000) Studies of surgical outcome after patellar tendinopathy: clinical significance of methodological deficiencies and guidelines for future studies. Victorian Institute of Sport Tendon Study Group. Scand J Med Sci Sports 10:2-11

8. van Dijk CN, van Sterkenburg MN, Wiegerinck JI, Karlsson J, Maffulli N (2011) Terminology for Achilles tendon related disorders. Knee Surgery Sport Traumatol Arthrosc 19:835-841

9. Downs SH, Black N (1998) The feasibility of creating a checklist for the assessment of the methodological quality both of randomised and non-randomised studies of health care interventions. J Epidemiol Community Health 52:377-384

10. Duthon VB, Lübbeke A, Duc SR, Stern R, Assal M (2011) Noninsertional Achilles tendinopathy treated with gastrocnemius lengthening. Foot Ankle Int 32:375-379

11. Johnston E, Scranton P, Pfeffer GB (1997) Chronic disorders of the Achilles tendon: results of conservative and surgical treatments. Foot Ankle Int 18:570-574

12. de Jonge $\mathrm{S}$, van den Berg C, de Vos RJ, van der Heide HJL, Weir A, Verhaar JAN, Bierma-Zeinstra SMA, Tol JL (2011) Incidence of midportion Achilles tendinopathy in the general population. Br J Sports Med 45:1026-1028

13. Kvist H, Kvist M (1980) The operative treatment of chronic calcaneal paratenonitis. J Bone Joint Surg Br 62:353-357

14. Kvist M (1994) Achilles tendon injuries in athletes. Sports Med 18:173-201

15. Lohrer H, Nauck T (2014) Results of operative treatment for recalcitrant retrocalcaneal bursitis and midportion Achilles tendinopathy in athletes. Arch Orthop Trauma Surg 134:1073-1081

16. Longo UG, Ramamurthy C, Denaro V, Maffulli N (2008) Minimally invasive stripping for chronic Achilles tendinopathy. Disabil Rehabil 30:1709-1713

17. Lysholm J, Wiklander J (1987) Injuries in runners. Am J Sports Med 15:168-171

18. Maffulli N, Binfield PM, Moore D, King JB (1999) Surgical decompression of chronic central core lesions of the Achilles tendon. Am J Sports Med 27:747-752

19. Maffulli N, Longo UG, Loppini M, Denaro V (2010) Current treatment options for tendinopathy. Expert Opin Pharmacother $11: 2177-2186$ 
20. Maffulli N, Oliva F, Testa V, Capasso G, Del Buono A (2013) Multiple percutaneous longitudinal tenotomies for chronic Achilles tendinopathy in runners: a long-term study. Am J Sports Med 41:2151-2157

21. Maffulli N, Testa V, Capasso G, Oliva F, Panni AS, Longo UG, King JB (2008) Surgery for chronic Achilles tendinopathy produces worse results in women. Disabil Rehabil 30:1714-1720

22. Maquirriain J (2013) Surgical treatment of chronic achilles tendinopathy: long-term results of the endoscopic technique. J Foot Ankle Surg 52:451-455

23. Martin RL, Manning CM, Carcia CR, Conti SF (2005) An outcome study of chronic Achilles tendinosis after excision of the Achilles tendon and flexor hallucis longus tendon transfer. Foot Ankle Int 26:691-697

24. Naidu V, Abbassian A, Nielsen D, Uppalapati R, Shetty A (2009) Minimally invasive paratenon release for non-insertional Achilles tendinopathy. Foot Ankle Int 30:680-685

25. Nawoczenski DA, Barske H, Tome J, Dawson LK, Zlotnicki JP, Digiovanni BF (2015) Tendinopathy: strength and functional outcomes. J Bone Joint Surg Am 97:99-105

26. Nelen G, Martens M, Burssens A (1989) Surgical treatment of chronic Achilles tendinitis. Am J Sports Med 17:754-759

27. Ohberg L, Lorentzon R, Alfredson H (2001) Good clinical results but persisting side-to-side differences in calf muscle strength after surgical treatment of chronic Achilles tendinosis: a 5-year follow-up. Scand J Med Sci Sports 11:207-212

28. Paavola M, Kannus P, Orava S, Pasanen M, Järvinen M (2002) Surgical treatment for chronic Achilles tendinopathy: a prospective seven month follow up study. Br J Sports Med 36:178-182

29. Paavola M, Orava S, Leppilahti J, Kannus P, Järvinen M (2000) Chronic Achilles tendon overuse injury: complications after surgical treatment. An analysis of 432 consecutive patients. Am J Sports Med 28:77-82
30. Pearce CJ, Carmichael J, Calder JD (2012) Achilles tendinoscopy and plantaris tendon release and division in the treatment of non-insertional Achilles tendinopathy. Foot Ankle Surg $18: 124-127$

31. Sarimo J, Orava S (2011) Fascial incision and adhesiolysis combined with radiofrequency microtenotomy in treatment of chronic midportion achilles tendinopathy. Scand J Surg 100:125-128

32. Schepsis AA, Leach RE (1987) Surgical management of Achilles tendinitis. Am J Sports Med 15:308-315

33. Steenstra F, van Dijk CN (2006) Achilles tendoscopy. Foot Ankle Clin 11:429-438

34. van Sterkenburg MN, van Dijk CN (2011) Mid-portion Achilles tendinopathy: why painful? An evidence-based philosophy. Knee Surg Sports Traumatol Arthrosc 19:1367-1375

35. Tallon C, Coleman BD, Khan KM, Maffulli N (2001) Outcome of surgery for chronic Achilles tendinopathy. A critical review. Am J Sports Med 29:315-320

36. Testa V, Capasso G, Benazzo F, Maffulli N (2002) Management of Achilles tendinopathy by ultrasound-guided percutaneous tenotomy. Med Sci Sports Exerc 34:573-580

37. Thermann H, Benetos IS, Panelli C, Gavriilidis I, Feil S (2009) Endoscopic treatment of chronic mid-portion Achilles tendinopathy: novel technique with short-term results. Knee Surg Sport Traumatol Arthrosc 17:1264-1269

38. Wiegerinck JI, Kerkhoffs GM, van Sterkenburg MN, Sierevelt IN, van Dijk CN (2013) Treatment for insertional Achilles tendinopathy: a systematic review. Knee Surg Sport Traumatol Arthrosc 21:1345-1355

39. Zwiers R, Wiegerinck JI, van Dijk CN (2014) Treatment of midportion Achilles tendinopathy: an evidence-based overview. Knee Surg Sport Traumatol Arthrosc. doi:10.1007/s00167-014-3407-5 